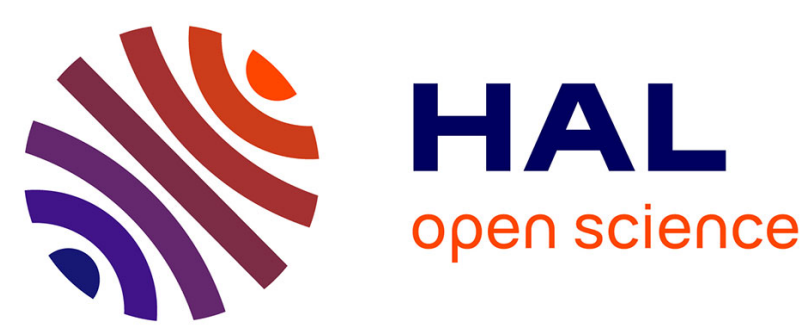

\title{
Selling and Saving Energy: Energy Efficiency Obligations in Liberalized Energy Markets
}

Louis-Gaëtan Giraudet, Matthieu Glachant, Jean-Philippe Nicolaï

\section{To cite this version:}

Louis-Gaëtan Giraudet, Matthieu Glachant, Jean-Philippe Nicolaï. Selling and Saving Energy: Energy Efficiency Obligations in Liberalized Energy Markets. Energy Journal, 2020, 41 (01), 10.5547/01956574.41.SI1.lgir . hal-03109922

\section{HAL Id: hal-03109922}

https://hal-mines-paristech.archives-ouvertes.fr/hal-03109922

Submitted on 13 Jul 2021

HAL is a multi-disciplinary open access archive for the deposit and dissemination of scientific research documents, whether they are published or not. The documents may come from teaching and research institutions in France or abroad, or from public or private research centers.
L'archive ouverte pluridisciplinaire $\mathbf{H A L}$, est destinée au dépôt et à la diffusion de documents scientifiques de niveau recherche, publiés ou non, émanant des établissements d'enseignement et de recherche français ou étrangers, des laboratoires publics ou privés. 


\title{
Selling and Saving Energy: \\ Energy Efficiency Obligations in Liberalized Energy Markets
}

\author{
Louis-Gaëtan Giraudet* Matthieu Glachant; Jean-Philippe Nicolai ${ }^{\ddagger}$
}

September 8, 2020

\begin{abstract}
In Europe, energy efficiency obligations are imposed on energy retailers competing in liberalized energy markets. They comply by subsidizing energy efficiency investments made by energy end-users within or outside their customer base. We develop a model describing how competition in the energy market affects compliance strategies. We find that, instead of selecting the most cost-effective investments options, firms may either target their most elastic customers, which enables them to increase their retail price, or their competitor's customers, which protects their sales. Allowing firms to trade obligations can restore cost-effectiveness, but reduces consumer surplus. Overall, the degree of flexibility that should be incorporated into such programs crucially depends on the degree of heterogeneity across investment costs and the relative weights governments assign to cost-effectiveness and consumer surplus.
\end{abstract}

Keywords: Energy efficiency; Imperfect competition; Information asymmetry; Internal and external compliance.

Classification JEL : D82; L13; L22; L94; Q41.

\footnotetext{
${ }^{*}$ Ecole des Ponts ParisTech, Centre international de recherche sur l'environnement et le développement (CIRED). Email: giraudet@centre-cired.fr

${ }^{\dagger}$ MINES ParisTech - PSL, CERNA. Email: matthieu.glachant@mines-paristech.fr

${ }^{\ddagger}$ EconomiX-CNRS, University of Paris Nanterre and ETH Zürich, Chair of Integrative Risk Management and Economics. E-mail: nicolai.jeanphilippe@parisnanterre.fr
} 


\section{Introduction}

Energy efficiency obligations (EEOs) are a widespread, yet little-discussed, policy tool. In the most general sense, EEOs consist of energy saving targets imposed by governments on energy companies. The targets can be fulfilled in a number of ways. The most common strategy is to have energy retailers grant subsidies to energy end-users for investing in energy efficiency (home insulation, heating system upgrades, efficient light bulbs, etc.). Energy retailers may also engage in educational and information programs, energy audits, loan programs. Energy savings are typically certified ex ante using standardized engineering calculations; the ensuing certificates serve as a proof of compliance.

EEOs have dramatically expanded over the past ten years. They are now present in 47 jurisdictions, including 26 US states, 15 EU member states, and large economies such as China and Brazil. According to the IEA (2018), they triggered $\$ 26$ billion investment in 2015, thereby contributing $12 \%$ of global energy efficiency investment. As of $2017,18 \%$ of global final energy use was covered by these programs.

Forcing energy retailers to reduce their sales may seem paradoxical, if not economically irrelevant. The justification put forward by policy-makers typically relies on three arguments. The first is general and applies to any energy efficiency policy: by reducing pollution externalities and a country's dependence on foreign energy sources, energy savings create social value 1 . Second, and more specifically, it is increasingly documented that consumers miss privately profitable energy saving opportunities (Allcott and Greenstone, 2012; Gillingham and Palmer, 2014). Thanks to their close connection with end-users, energy utilities are fit for addressing these so-called "internalities" and nudge consumers towards more conservation. Third, energy retailers are supposed to own more information than the public regulator on energy saving opportunities, owing to the data they collect from their large customer base. This gives them a comparative advantage in the identification of the most cost-effective measures (Joskow and Marron,1992; Stoft and Gilbert, 1994).

\footnotetext{
${ }^{1}$ From an energy user's perspective, energy efficiency obligations amount to combining a tax on energy and a subsidy for energy efficiency. Taking this view, Giraudet and Quirion (2008) have shown that obligations are only a second-best solution to the externality problem, which is ideally addressed by pure externality pricing.
} 
How the broad principles defining EEOs translate into effective policy design is highly specific to the energy markets they are implemented in. In the United States, obligations are primarily imposed on local distribution monopolies regulated by state public utility commissions and compliance costs are recovered through regulated charges paid by all customers in the network. In Europe, obligations are mostly imposed on retailers competing in liberalized energy markets. Compliance costs are eventually recovered through market adjustments in retail energy prices. Like in the United States, obligated energy retailers can target their own customers - a provision we refer to as 'internal compliance.' The fact that they compete with other obligated retailers however adds at least two sources of flexibility. One is that they can promote energy efficiency outside their own customer base - a provision we refer to as 'external compliance.' Another one is that they can also meet (part of) their obligation by purchasing energy savings certificates from other obligated firms. While most of the programs implemented in Europe authorize external compliance, trading between obligated firms is much less widespread. We give more detail on the design of EEOs in Section 2 .

The literature on energy efficiency obligations is scarce and focused on the regulated monopoly context that prevails in the United States. Using a principal-agent framework, a few papers have examined the optimal rate structure that a public utility commission should offer to encourage conservation efforts by a regulated monopoly, assuming various forms of imperfect information about consumer preferences (Lewis and Sappington, 1992; Chu and Sappington, 2012, 2013; Wirl, 1995, 2015). Their results, however, need not carry over to the liberalized yet imperfectly competitive context that prevails in Europe, and this for at least two reasons. First, competing energy retailers can set their prices freely and the extent to which they can pass-through compliance costs onto retail prices therefore centrally depends on energy market conditions. Second, the possibility of external compliance may induce retailers not to exploit the superior information they possess about their customers. Allowing obligated parties to trade energy saving certificates can nevertheless dissipate this threat.

To the best of our knowledge, the incentives energy efficiency obligations specifically create in liberalized energy markets have not been examined. This paper contributes to filling this gap 
by examining the conditions under which they effectively induce competing energy retailers to leverage private information about end-users. To capture the key aspects of competition at play in energy markets, we rely on a Hotelling model whereby two energy retailers supply energy to a continuum of customers. Crucially, energy users differ along two dimensions that are privately known to their current retailer: their individual price elasticity of demand, and the cost they incur upon investing in energy efficiency. Within that framework, we compare the incentive and distributional properties of a variety of energy efficiency obligation designs. Keeping the level of the obligation exogenous, we pay particular attention to the following design features: (i) whether or not retailers are allowed to promote energy efficiency outside their customer base; (ii) whether they can trade certified energy savings. In examining these flexibility options, we assume throughout equality of average investment costs across retailers in order to rule out straightforward effects arising from heterogeneity and instead focus on the very effect of competition.

Our analysis highlights that imperfect competition in energy markets impairs the costeffectiveness of energy efficiency obligations, for several reasons. First, when energy retailers are only allowed to comply internally, they will harvest low-cost investment opportunities only to the extent that cost heterogeneity is high enough. Otherwise, they will rather target their most elastic customers, which enables them to increase their retail price. Second, allowing external compliance does no better. Relying on external compliance indeed protects a retailer's sales. With both firms facing the same incentive, our model predicts that a subgame perfect equilibrium will arise with generalized external compliance, provided that cost heterogeneity is low enough. This again is bad news for cost-effectiveness, since retailers know nothing about the distribution of investment costs among their competitors' customers and therefore cannot exploit the cheapest options. Third, an encouraging result it that allowing the trading of obligations mitigates the free-riding incentives underlying generalized external compliance. The argument here is different from the flexibility one usually invoked about trading. Our point is that trading obligations serves as a binding commitment to the cost-effective selection rule. 
Our results have important policy implications. In a nutshell, granting more flexibility through external compliance does not necessarily increases cost-effectiveness. As overall costeffectiveness crucially depends on the degree of heterogeneity among investment costs, policymakers should carefully assess energy efficiency potentials - in particular the type of eligible measures - in order to design adequate flexibility provisions. Lastly, allowing the trading obligations seems like a sensible way to mitigate the adverse effects of external compliance.

The remainder of the paper is as follows. Section 2 provides further background about energy efficiency obligation programs. Section 3 introduces the model. Sections 4 and 5 examine different obligation designs. Section 6 studies extensions. Section 7 draws policy implications and concludes.

\section{Background on European Energy Efficiency Obligations}

EEOs were imposed in Europe in the wake of the deregulation movement that affected energy markets in the 2000s. The approach was pioneered by the United Kingdom in 2002. Italy, Denmark and France followed the British example and implemented their own EEOs in 20052006. These programs became known as 'white certificate obligations' (Giraudet and Finon, 2015). The European Energy Efficiency Directive of 2012 (2012/27/EU) further expanded the number of EEOs, which now exist in 15 countries, including Austria, Bulgaria, Croatia, Greece, Ireland, Latvia, Luxembourg, Malta, Slovenia, Spain and Poland (Fawcett et al., 2018).

European EEOs significantly differ from one another in their architecture. An extensive comparison can be found in a recent OECD/IEA report (2017). Let us briefly emphasize the significance of those design features of greatest interest for our later analysis. First, the majority of the programs places the obligation on energy retailers - in most cases those selling electricity and natural gas (Foster et al., 2016). A few programs alternatively target energy distributors (in particular in Italy). The key difference between the two approaches is that distributor-imposed obligations never allow external compliance (e.g., electricity retailers promoting natural gas savings). As we are mostly interested in external compliance, we focus on supplier-imposed obligations in the remaining. Lastly, trading among obligated parties is 
rare and only allowed in France, the United Kingdom, and Poland.

To fix ideas, we now provide a detailed description of the French program. The French program has grown to becoming the most stringent in the world - according to the IEA (2018), it targets a $0.9 \%$ annual reduction of national energy use, to be compared with a global average of $0.4 \%$ and countries like China, the United States and Brazil falling below 0.1\%. With obligations falling on all fuels and possibly fulfilled in all non EU-ETS sectors, it is also one among those with the broadest coverage (IEA, 2017). Lastly, it accommodates the key components of interest of our analysis, namely external compliance and trading.

Individual obligations are assigned to energy retailers in proportion to their sales in the residential market, with differing coefficients depending on the fuel considered. Noncompliance is punished with a $€ 20$ fine per missing MWh (lifetime discounted). Excess savings can be carried over for compliance in future periods. By design, compliance with individual targets extensively relies on ex ante standardized savings: for any measure implemented, obligated parties are granted by the regulator a pre-defined amount of energy savings - the so-called certificates - in exchange for a proof of implementation (e.g., invoice of insulation installation) ${ }^{2}$ Given the well-documented discrepancy between predicted and realized energy savings (Metcalf and Hassett, 1999; Fowlie et al., 2018), such certificates need not reduce the obligated party's sales by the exact same amount. They may not even reduce sales at all if the measure is implemented on the premise of a competitor's customer.

Although no public data is available to assess the significance of external compliance, anecdotal evidence suggests it is pervasive. Electricity suppliers routinely promote natural gas-saving measures (e.g., condensing boiler) to customers to whom they exclusively sell electricity. Likewise, natural gas suppliers promote efficient lighting to their gas-only customers. Department stores such as Carrefour and E. Leclerc that derive an obligation from their gasoline sales typically fulfill it with coupons for energy efficient appliances (powered with electricity they do not sell).

Obligated parties are allowed to trade energy savings, both bilaterally and on a spot market.

\footnotetext{
${ }^{2}$ Non-standardized measures can also be implemented. After an audit has been conducted, energy savings are still certified on an ex ante basis. From 2006 to 2017, such specific measures never contributed more than $6 \%$ of the obligation annually.
} 
Either way, transactions are recorded on an online platform (www.emmy.fr). The market can be supplied by non-obligated, yet eligible, parties such as local communities. With 288 TWh and 179 TWh traded in 2019 and 2018, respectively, trading fulfills a significant share of the $533 \mathrm{TWh}$ annual abatement target $!^{3}$ After a decade spent within the $€ 2-4 / \mathrm{MWh}$ range, the price of traded certificates recently soared from a yearly average of $€ 4.16$ in 2017 to $€ 5.54$ in 2018 to $€ 7.33$ in 2019 . Valued at the latter price, the current obligation has an annual cost of $€ 3.9$ billion to obligated parties.

\section{The model}

We adopt the Hotelling framework of horizontal differentiation to study network industries (Hotelling, 1929) ${ }^{4}$ In Section 6, we relax some of our assumptions and discuss the robustness of the results.

\subsection{Assumptions}

The model involves two energy retailers competing to supply a continuum of energy users. Energy users are uniformly distributed on a segment $[0,1]$ and the two firms are located at the two ends of the segment. Each consumer uses either 0 or 1 unit of energy. The consumer located in $x$, consuming 1 unit and supplied by firm $i$ (with $i=1,2$ ), enjoys utility:

$$
u_{i}(x):=V-t\left|x-x_{i}\right|
$$

where $V$ is a fixed surplus from energy service (e.g., heating, lighting), $x_{i}$ is retailer $i$ 's location (hence $x_{1}=0$ and $x_{2}=1$ ) and $t\left|x-x_{i}\right|$ denotes the cost of being supplied by $i$. Utility is zero if the consumer does not use energy service. In this framework, market power arises

\footnotetext{
${ }^{3}$ Own calculation using data from www.emmy.fr. Savings can be traded several times before being counted towards targets. As multiple trades are not flagged on the platform, our calculation is not immune from double counting.

${ }^{4}$ A closely related approach is that of Laffont et al. (1998), who use the Hotelling model to examine network competition in the telecommunication industry. Our focus on the energy sector however implies important adjustments. While Laffont et al. (1998) consider differentiated products and access charges to a competitor's network, we consider a homogenous product supplied by networks towards which consumers show different degrees of loyalty.
} 
from the transport cost parameter $t$ which reflects a consumer's elasticity of demand towards a given retailer. In the context of energy markets, this may stem from varying levels of loyalty to a retailer or other demand-side switching costs coming from explicit clauses in contracts, reward programs, or psychological factors such as brand loyalty and procrastination (Klemperer, 1995).

We assume throughout that $V$ is large enough so that all consumers buy energy in a business-as-usual context without regulation - this assumption will be mathematically specified below - and that both retailers face the same constant marginal cost, normalized to 0 .

Ignoring for now that consumers can invest in energy efficiency, the market shares enjoyed by Firms 1 and 2 upon charging prices $p_{1}$ and $p_{2}$ are determined by the "location" of the energy user who is indifferent between purchasing energy from either of the two firms. This location $\tilde{x}$ is defined by the indifference condition $u_{1}(\tilde{x})-p_{1}=u_{2}(\tilde{x})-p_{2}$, leading to

$$
\tilde{x}\left(p_{1}, p_{2}\right)=\frac{1}{2}+\frac{p_{2}-p_{1}}{2 t}
$$

The ensuing market equilibrium is straightforward. Both faced with demand $\tilde{x}\left(p_{1}, p_{2}\right)$, Firms 1 and 2 set their prices so as to maximize profits $\Pi_{1}:=p_{1} \times \tilde{x}\left(p_{1}, p_{2}\right)$ and $\Pi_{1}:=$ $p_{2} \times\left(1-\tilde{x}\left(p_{1}, p_{2}\right)\right)$, respectively. It follows that each firm serves half of the market at a uniform price:

$$
p_{1}=p_{2}=t
$$

In this linear setting, parameter $t$ represents the elasticity of demand and thus determines the gap between the marginal cost (here assumed to be zero) and the energy price. We assume full market coverage throughout by imposing non-negative surplus on the consumer located in $x=1 / 2: u_{i}=V-t / 2 \geq t$, equivalent to $V \geq 3 t / 2:^{5}$

We now consider customers investing in energy efficiency. In doing so, customers keep

\footnotetext{
${ }^{5}$ Note that, if we added to the game a preliminary stage in which energy retailers chose their location before setting their price, the two energy retailers would locate at the two extremities, as is assumed here. It is however well known that the socially optimal location pair is $(1 / 4,3 / 4)$.
} 
Figure 1: Market equilibrium in business as usual

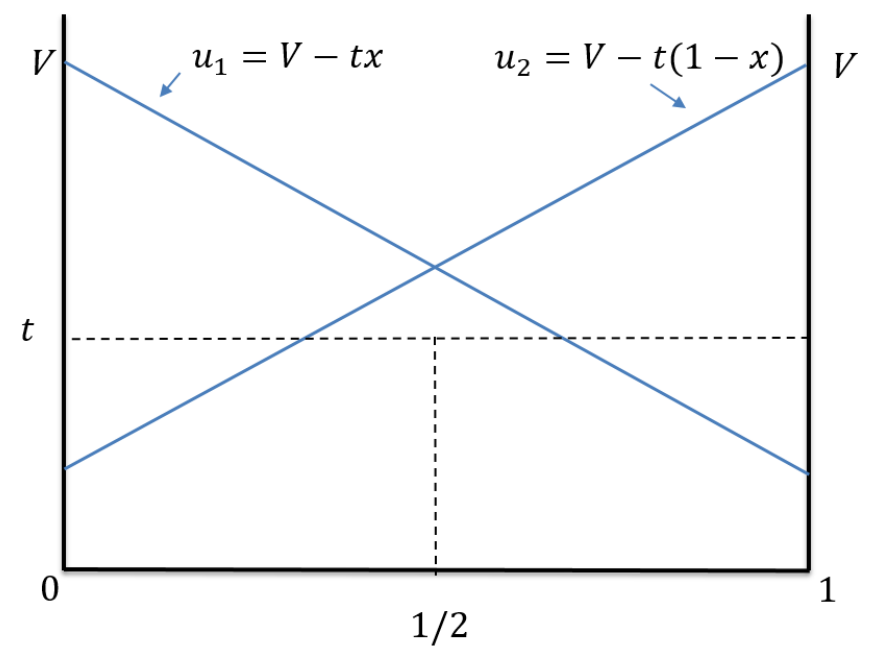

their energy service and their connection to the network unchanged ${ }^{6}$ so utility remains $u_{i}(x)$. Consumers simply use less energy. For the sake of simplicity, we assume that energy use falls to zero after investment. We further assume that investment costs are heterogeneous and can take two values, high $\bar{I}$ and low $\underline{I}$ (with $\underline{I}<\bar{I}$ ), uniformly distributed across consumers over $[0,1]$. Such heterogeneity arises for instance from differences in thermal integrity across the building stock. Lastly, we assume that investing costs more than purchasing energy at the market price $(\underline{I}>t)$ so there is no investment in the business-as-usual scenario.

\subsection{Information structure}

Informational assumptions are crucial in our analysis of how well energy efficiency obligations induce energy retailers to leverage private information. We consider two sources of information asymmetries. In both cases, we assume that an energy retailer is better informed about its own customers than about its competitor's.

The first source of asymmetric information is a customer's elasticity. We consider that the

\footnotetext{
${ }^{6}$ We technically abstract from changes in the marginal cost of energy services after investment, which typically cause rebound effects.
} 
location of a customer $x$ is a noisy signal $s$ known by her own retailer:

$$
s(x):=x+\epsilon
$$

where $\epsilon$ is a noise term uniformly distributed over the interval $[-e,+e]$. The signal can stem from the duration of the pre-existing contract, the age of the customer, etc.7 In contrast, a retailer owns less information about its competitor's customers: Retailer 1 only knows that Retailer 2's customers are located beyond 1/2 and Retailer 2 only knows that Retailer 1's ones lie below $1 / 2$.

The second source of information asymmetry is investment cost. We assume that a retailer perfectly knows its customers' investment costs, which it can infer from, say, its database of energy consumption patterns. This piece of information, however, is not perfectly known to its competitor, which only knows the distribution of investment costs among its competitor's customers.

\subsection{Energy efficiency obligations}

We introduce an energy efficiency obligation imposing sales reduction on each retailer by a quantity $\alpha$. In line with the prevailing regulatory approach consisting in awarding energy savings certificates in exchange for proofs of investment (e.g., invoices), we consider that energy retailers can only meet their obligation by inducing a certain number of investments. In other words, a retailer cannot comply by inducing energy use reductions without investment.

We model the energy efficiency obligation as a game played by the two retailers. The timing of the game is as follows:

1. Each firm chooses which consumers to encourage to meet its obligation $\alpha$.

2. The selected customers receive a subsidy and they invest.

3. Each firm sets its price and payoffs are realized.

\footnotetext{
${ }^{7}$ Technically, this noisy specification allows us to avoid discontinuities in energy demand, a usual problem in Hotelling models which would seriously complicate equilibrium analysis.
} 
We focus on interior solutions and therefore impose the following conditions on the pa-

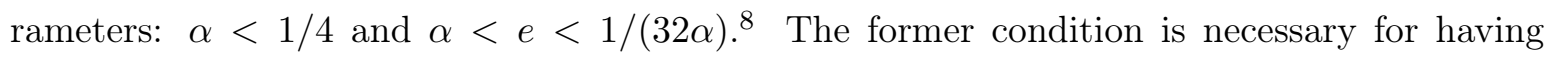
retailers exclusively target low-cost consumers; the latter allows prices and quantities to be non-negative. These restrictions, however, do not qualitatively alter the results.

\section{Energy efficiency obligations with internal compliance only}

In this section, we analyze the simplest scheme in which only internal compliance is allowed. That is, Firm 1 can only select energy users from among those located below $1 / 2$ and, symmetrically, Firm 2 can only proceed with those located above.

It directly follows from the above assumptions that the social cost of achieving the regulatory target is minimized when each retailer targets $\alpha$ low-cost consumers. From a costminimization perspective, the specific location of these customers is indeed irrelevant as they derive utility $u_{i}$ regardless of whether they invest or not. The question of interest is whether the retailers will select these consumers in equilibrium.

Subsidizing customers with high elasticity of demand. To answer this question, it will be easier to consider first a strategy profile in which both retailers seek to target their high-elasticity customers instead of their low-cost ones. As we shall see, such a strategy will allow them to raise their price.

Let us consider Firm 1 and recall that a customer's location is only perceived as a noisy signal by the firm. The best Firm 1 can do is to select the $\alpha$ customers with the highest signals. To do so, Firm 1 will select all customers whose signal $s$ falls within $[y+e, 1 / 2+e]$, where $y<1 / 2$ is a threshold to be determined above which compliance is ensured by selecting $\alpha$ customers. Our objective is to characterize energy demand after investment.

It is pretty obvious that the firm infers location $x=1 / 2$ upon observing signal $1 / 2+e$. Formally:

$$
\operatorname{Pr}[x=1 / 2 \mid s=1 / 2+e \text { and } x \leq 1 / 2]=1 .
$$

\footnotetext{
${ }^{8} \alpha<1 /(32 \alpha)$ implies that $\alpha<1 /(4 \sqrt{2})$ which in turn is consistent with $\alpha<1 / 4$.
} 
A lower signal is less informative: Upon observing $s$, Firm 1 can only infer that the customer's true location $x$ falls with equal probability within $[s-e, 1 / 2]$.

Now take the customer whose true location is $x$. Her probability of being selected, based on the reception of all signals within $[y+e, 1 / 2+e]$, and given the distribution of noise $\epsilon$, is

$$
\operatorname{Pr}\left([x \mid s \in[y+e, 1 / 2+e])=\int_{y}^{x} \frac{1}{2 e} d t=\frac{x-y}{2 e} .\right.
$$

The cumulative distribution of consumers thus selected is

$$
F(x):=\int_{y}^{x} \frac{z-y}{2 e} d z=\frac{1}{4 e}(x-y)^{2}
$$

for $x \in[y, 1 / 2]$ and $F(x)=0$ for $x \in[0, y)$. The unknown $y$ is determined by the compliance condition $F(1 / 2)=\alpha$, yielding $y=\frac{1}{2}-2 \sqrt{\alpha e}$. Plugging this into $\sqrt{4}$, we obtain:

$$
F(x)= \begin{cases}\frac{1}{4 e}\left(x-\frac{1}{2}+2 \sqrt{\alpha e}\right)^{2} & \text { if } x \in[1 / 2-2 \sqrt{\alpha e}, 1 / 2] \\ 0 & \text { if } x \in[0,1 / 2-2 \sqrt{\alpha e}) .\end{cases}
$$

The density of selected consumers therefore is

$$
f(x)= \begin{cases}\frac{1}{2 e}\left(x-\frac{1}{2}+2 \sqrt{\alpha e}\right) & \text { if } x \in[1 / 2-2 \sqrt{\alpha e}, 1 / 2] \\ 0 & \text { if } x \in[0,1 / 2-2 \sqrt{\alpha e})\end{cases}
$$

The density function of those customers who continue to use energy after others have been encouraged to invest is $1-f(x)$. The exact same reasoning symmetrically applies to Firm 2 . Figure 2 pictures the resulting density function at the market level. The area under the curve is total energy demand after $2 \alpha$ customers have invested.

In the third stage of the game, knowing the location of the indifferent consumer $\tilde{x}\left(p_{1}, p_{2}\right)$, the energy retailers set their prices so as to maximize the profit they derive from energy sales after targeted customers have invested. The demand functions faced by Retailers 1 and 2 are $\tilde{x}-F(\tilde{x})$ and $1-2 \alpha-(\tilde{x}-F(\tilde{x}))$, respectively. 
Figure 2: Customer density when both retailers subsidize the customers with the highest elasticity of demand

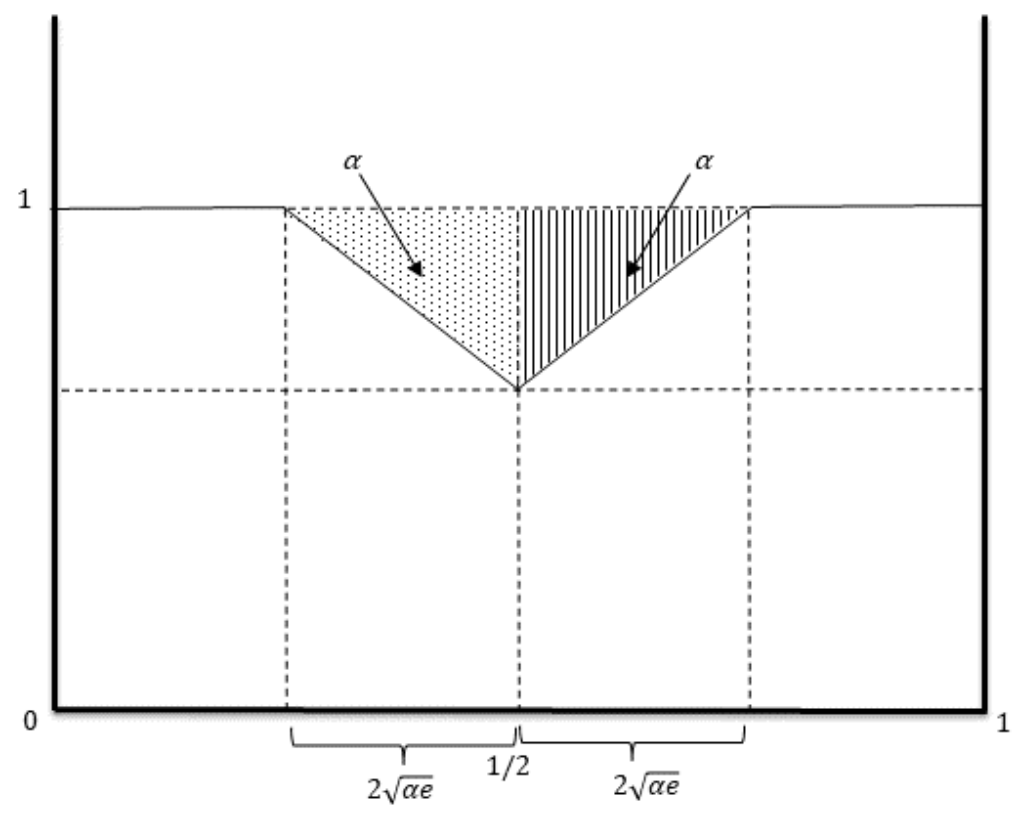


Under this assumption, the candidate pair of equilibrium prices is the solution of:

$$
\begin{aligned}
\max \Pi_{1}\left(p_{1}, p_{2}\right) & =[\tilde{x}-F(\tilde{x})] \times p_{1} \\
\max \Pi_{2}\left(p_{1}, p_{2}\right) & =[1-2 \alpha-(\tilde{x}-F(\tilde{x}))] \times p_{2}
\end{aligned}
$$

As the demand functions faced by Retailers 1 and 2 are not continuously differentiable, each domain of $\tilde{x}$ needs to be examined separately. The complete analysis of the different cases, provided in Appendix 8.1, results in the following lemma:

Lemma 1. When both retailers subsidize their high-elasticity customers, each one serves one half of the market $(\tilde{x}=1 / 2)$ and the equilibrium price is

$$
p_{l}^{*}=\frac{1-2 \alpha}{1-\sqrt{\alpha / e}} t
$$

Proof. See Appendix 8.1

This price is higher than the business-as-usual price $t$. Denying energy consumption to consumers with the highest demand elasticity allows energy retailers to raise their price and thus pass-through (part of) the subsidy cost onto those customers who did not invest. The gap widens with the obligation level $\alpha$. It also grows with more accurate signals on individual demand (i.e., a lower $e$ ), making it easier to target truly marginal customers.

While increasing prices is good news for profits, there is a downside to it: half of the targeted customers invest at a high cost, and thus need higher incentives than do the other half. Calculating the total incentive cost is straightforward. A retailer leveraging private information on investment cost is able to offer each of its customers the lowest subsidy needed to induce investment - that is, the subsidy which just bridges the gap between the energy price $t$, which the consumer expects to pay in the absence of investment 9 and her investment cost. 10 As the net utility for an individual located in $x$ is $V-t x-t$ in business as usual and

\footnotetext{
${ }^{9}$ We assume here that individual customers take the initial price $t$ as given. They do not anticipate that their joint investment decisions will lead ex post to price $p(\alpha)$.

${ }^{10}$ This ability to price discriminate is an important difference with public subsidy programs, in which subsidy amounts typically do not differ across recipients (beyond some observable eligibility criteria such as income
} 
$V-t x-I$ after investment, the subsidy is equal to $\bar{I}-t$ and $\underline{I}-t$ for high-cost and low-cost customers, respectively. Ultimately, the total incentive cost for the retailer is $\alpha(E(I)-t)$.

Subsidizing customers with low investment costs. Another strategy consists in targeting those customers who invest at low cost $\underline{I}$, thereby reducing the total subsidy cost to $\alpha(\underline{I}-t)$. The retailer then needs to choose whom among the low-cost customers to subsidize. The best a retailer can do to pass-through compliance costs onto retail prices is to target the less loyal customers within this low-cost group. The ensuing analysis is very similar to that leading to Lemma 1. Each retailer will select the mass $\alpha$ of customers with the highest signals from among the low-cost ones. This selection process only differs from the previous one in that the density of customers is halved. Figure 3 displays the density obtained after investment and compares it with that of the previous case. Following the same steps as in Lemma 1, we show in Appendix 8.2 that:

Lemma 2. When both retailers subsidize low investment-cost customers, each one serves one half of the market and the equilibrium price is

$$
p_{c}^{*}=\frac{1-2 \alpha}{1-\sqrt{\alpha /(2 e)}} t
$$

Proof. See Appendix 8.2

It unambiguously follows that $p_{l}^{*}>p_{c}^{*}$. Targeting low-cost customers weakens a retailers' ability to raise price and deny energy consumption to low-elasticity customers. It however allows retailers to save on subsidy costs. Ultimately, how profits compare under the two strategy profiles is ambiguous and depends in particular on the investment cost differential. Substitutions and straightforward calculations detailed in Appendix 8.2 show that targeting low-cost customers is more profitable if

$$
\Delta I:=\bar{I}-\underline{I}>\Phi(\alpha, e)
$$

that occasionally apply). 
Figure 3: Customer densities under two different retailer strategies

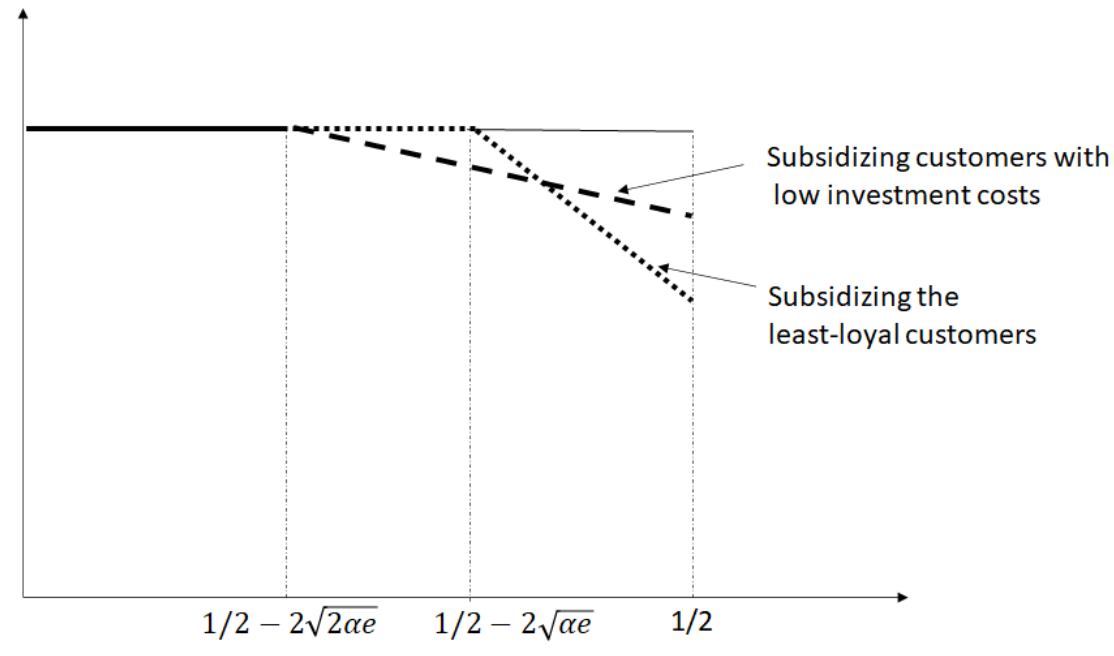

with:

$$
\Phi(\alpha, e):=\left(\frac{(1-2 \alpha)^{2}}{\alpha}\right)\left(\frac{1}{1-\sqrt{\alpha / e}}-\frac{1}{1-\sqrt{\alpha /(2 e)}}\right)
$$

The subgame perfect Nash equilibrium. Lemma 1 and 2 elicit two strategy profiles. It remains to examine whether and how they are consistent with equilibrium. We show in Appendix 8.3 that the condition (9) delineates two mutually exclusive equilibria.

Proposition 1. Under internal compliance, both retailers choose to subsidize customers with low investment costs if $\Delta I>\Phi(\alpha, e)$ holds. Otherwise, they both choose to subsidize the customers with the highest demand elasticity.

In both cases, prices are higher than in business as usual and they increase with the level of obligation $\alpha$. The price increase is however milder when they target low-cost customers.

Proof. See Appendix 8.3

The intuition of the proof is as follows. Consider the case where both retailers target the high-elasticity customers in the first stage and thus enjoy a higher profit than under the alternative targeting strategy. If, say, Retailer 2 deviates in the first stage by targeting lowcost customers, it needs to lower its price to retain its customers. If this occurs, the marginal customers of Retailer 1 will switch to Retailer 2 . Retailer 1 can only respond by cutting 
its price. As a result, market shares remain unchanged, but the price is lower. Unilateral deviation is therefore not profitable.

This proposition has important policy implications. As previously explained, minimizing social cost requires that retailers only subsidize low-cost customers. We establish here that imperfect competition in the energy market threatens achievement of this objective. Energy efficiency obligations endogenously reduce demand and thereby allow retailers to increase their price. When the investment cost differential is moderate, retailers prefer maximizing their price to saving on investment cost.

\section{$5 \quad$ Allowing external compliance}

We first consider programs whereby energy retailers are allowed to subsidize any customer in the market. We then consider a more flexible scheme whereby they can also subsidize investments out of their market.

\subsection{Compliance inside the market}

Subsidizing a competitor's customers implies that a retailer randomly selects customers without knowing their location nor their investment cost. Under our assumptions, such an external compliance cannot improve cost-effectiveness. At best, an external-compliance equilibrium can be as cost-efficient as an internal-compliance equilibrium in which retailers target highelasticity customers. This directly follows from the (simplifying) assumption that investment costs are heterogeneous across customers, but the shares of low-cost and high-cost customers are identical across retailers. We relax this assumption later. Given that retailers also randomly select locations, we can also anticipate that external compliance reduces the extent to which compliance costs are passed onto energy prices.

In order to identify incentives to deviate from internal compliance, we consider the two cases described in the previous section: both firms either subsidize their high-elasticity customers

or target their customers with low investment costs. As stated in Proposition 1, incentives ultimately depend on the size of the investment cost differential. 
The investment cost differential is low. We first consider the case where $\Delta I<\phi(\alpha, e)$ so that each retailer targets high-elasticity customers under internal compliance. When external compliance is allowed, it is easy to show that:

Lemma 3. When $\Delta I<\Phi(\alpha, e)$, both energy retailers fully rely on external compliance. The energy price after investment is then equal to the business-as-usual price. Retailers' profits are lower under external compliance than under internal compliance.

Proof. See Appendix 8.4

The intuition of the proof is as follows. First, retailers have limited information about their competitor's customers so the expected cost of subsidizing one is $E(I)-t$. There is no loss here relative to internal compliance. Second, subsidizing a competitor's customer allows a retailer to avoid reducing sales by a quantity $\alpha$ but lowers its ability to raise price. We show in the Appendix that the quantity effect dominates the price effect, thereby giving incentive to deviate from the internal-compliance equilibrium.

Under external compliance, the fact that both retailers randomly select customers implies that the customer density after investment remains flat relative to the business as usual. The obligation scheme induces a uniform demand reduction (see Figure 44, leading to the businessas-usual price.

External compliance thus prevents firms from passing through the cost of subsidies onto energy prices. Paradoxically, adding more flexibility - by allowing external compliance - harms firms' profit by inducing free riding.

The investment cost differential is high. Let us now focus on the case in which the energy retailers target their customers with low investment costs under internal compliance. This occurs when the investment cost differential is such that $\Delta I \geq \Phi(\alpha, e)$.

At a glance, relying on external compliance seems less profitable than in the previous case: it now increases the subsidy cost as each retailer subsidizes a mix of low-cost and high-cost customers. As market profits are unaffected by the investment cost differential, it is straightforward that internal compliance will dominate if $\Delta I$ is high. Conversely, there 
Figure 4: Equilibrium when both energy retailers target their rival's customers

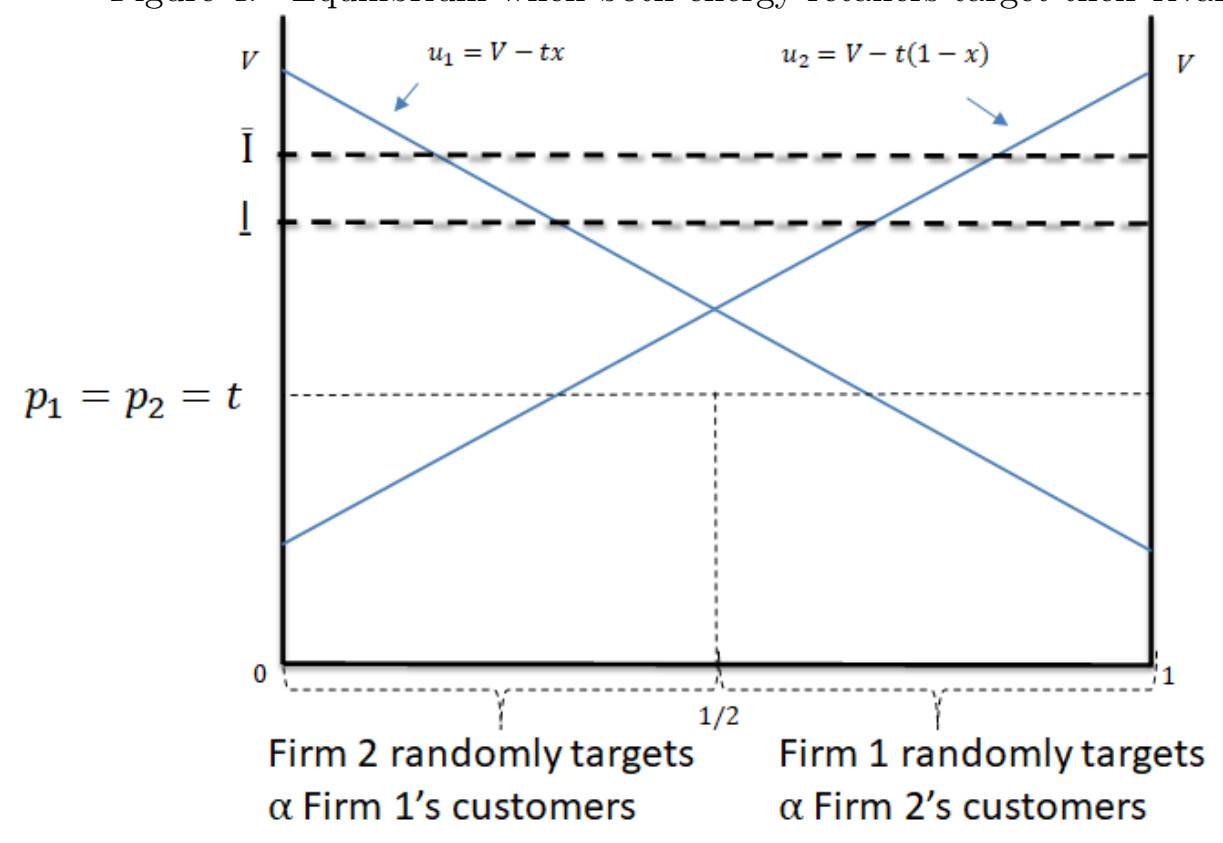

exists cases where deviation is profitable when the differential is lower, as we illustrate in back-of-the-envelope calculations provided in the Appendix. If both firms engage in fully external compliance, then the equilibrium price is equal to the business-as-usual price $t$. More specifically:

Lemma 4. When $\Delta I \geq \Phi(\alpha, e)$, there exists values of $\alpha$ and e such that full external compliance occurs if the investment cost differential is low.

Proof. See Appendix 8.5

We summarize the results of Lemmas 3 and 4 in a new proposition.

Proposition 2. Both retailers rely on external compliance when the investment cost differential $\Delta I$ is low. $\Delta I<\Phi(\alpha, e)$ is sufficient but not necessary for external compliance. If the condition for external compliance is not satisfied, energy retailers target their low-cost customers. Relative to internal compliance, fully external compliance has the following impact: 
(i) It weakly increases total investment cost.

(ii) The energy price falls to the business-as-usual level $t$.

(iii) Profits are lower

This analysis highlights a trade-off between cost-effectiveness and consumer surplus. Being less well informed about their competitor's customers, retailers are no longer able to target low-cost customers (which weakly increases cost) nor high-elasticity customers (which reduces their ability to influence prices).

Asymmetric investment costs across retailers. The result on investment costs decisively hinges upon the assumption that the distribution of investment costs is identical across the two customer bases. Relaxing this assumption obviously gives a more nuanced view on the costs and benefits of external compliance.

Let us revise our assumptions and examine this issue. To ease the comparison with Proposition 2, we keep the investment cost differential at the same level $\Delta I$ within each customer base and assume that Retailer 1's average customer invests at a lower cost. More specifically, after denoting $\underline{I}_{i}$ the lowest investment cost among the customers of Retailer $i$, we suppose that $\underline{I}_{1}<\underline{I}_{2}$. Under these assumptions, Proposition 1 is still relevant to the choice of targeting either high-elasticity or low-cost customers under internal compliance. Yet if allowed, Retailer 2 is now more prone to rely on external compliance than is Retailer 1 and this difference in incentives opens up room for cost-effective moves. Cost minimization, however, is no longer feasible with the obligation scheme for internal compliance prevents Retailer 1 from harvesting low-cost options within its own customer base while external compliance prevents Retailer 2 from leveraging private knowledge and target its low-cost customers.

Let us examine the two cases in greater detail:

- If $\Delta I<\Phi(\alpha, e)$, both suppliers target high-elasticity customers, leading to high prices and high average investment costs under internal compliance. Allowing external compliance makes it possible for both suppliers to target the rival's customer base. As in 
Lemma 3, Retailer 2 has incentives to target Retailer 1's customer base to avoid reducing its sales but also to take advantage of lower investment costs. On the other hand, Retailer 1 does not necessarily have an interest in targeting its rival's consumers because the amount of the investment costs would be higher. There is a trade-off between avoiding losing sales and increasing the amount of subsidies required. The difference with Lemma 3 is that when the gap between $\underline{I}_{1}$ and $\underline{I}_{2}$ is large enough, both retailers target Retailer 1's customer base. In this event, external compliance will save investment costs and lower the energy price (as Retailer 2 does not target high-elasticity customers anymore).

- If $\Delta I \geq \Phi(\alpha, e$.$) , each supplier targets its own low-cost customers under internal com-$ pliance. Again, if the cost differential between the two customer bases is large enough, they may target Retailer 1's customers if they are allowed to do so. This would reduce investment costs, as a necessary condition for this equilibrium to arise is that external compliance lowers the average subsidy for Retailer $2: \underline{I}_{2}-t>\underline{I}_{1}+\Delta I / 2-t$.

The following proposition summarizes our results.

Proposition 3. When investment costs are heterogeneous within and across customer bases and only internal compliance is allowed, energy efficiency obligations cannot minimize investment costs.

Relative to internal compliance, allowing a retailer to target its competitor's customer base can however reduce total investment cost if the cost differential between the two customer bases is large enough.

\subsection{Compliance outside the market}

In practice, obligations can be achieved in different sectors, thus allowing retailers to subsidize energy users outside their market (e.g., gasoline retailers offering vouchers for energy-efficient lightbulbs in France, as discussed in Section 2). In examining this case, we maintain our symmetry assumption and consider that incentive costs are the same whether a retailer selects 
Figure 5: Customer density when Firm 2 targets Firm 1's customers and Firm 1 targets customers from outside the market.

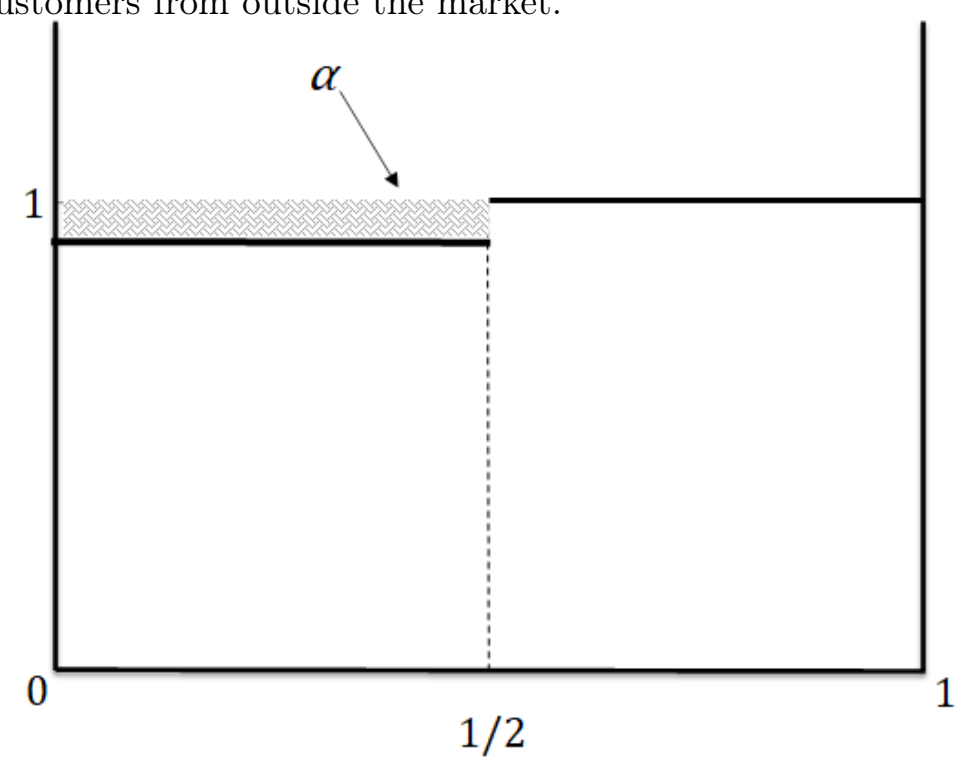

customers from among its competitor's base or from outside the market. This specification allows us to rule out results arising mechanically from cross-market heterogeneity.

We now show that retailers will never comply this way. To do so, we examine a retailer's incentive to deviate from the equilibria described in Proposition 2. Let us start with the scenario where $\Delta I$ is low so both retailers select their competitor's customers. The customer density is flat in this case.

As depicted in Figure 5, the density becomes asymmetric and discontinuous in $x=1 / 2$ if Retailer 1 unilaterally decides to comply outside the market, which necessarily alters the market equilibrium in the next stage. Assuming first that the indifferent customer is located beyond $1 / 2$, both firms maximize

$$
\begin{aligned}
& \max \Pi_{1}\left(p_{1}, p_{2}\right)=[1-\tilde{x}] \times p_{1} \\
& \max \Pi_{2}\left(p_{1}, p_{2}\right)=[\tilde{x}-\alpha] \times p_{2} .
\end{aligned}
$$


Deriving the first-order conditions and solving them for $p_{1}$ and $p_{2}$ yields

$$
p_{1}^{*}=t\left(1-\frac{4}{3} \alpha\right) ; \quad p_{2}^{*}=t\left(1-\frac{2}{3} \alpha\right)
$$

It follows that $p_{1}^{*}<p_{2}^{*}$ and hence $\tilde{x}>1 / 2$ : Increasing demand on the other side of the market leads Retailer 1 to price more aggressively in order to gain market share. This however brings both prices below their business-as-usual level $t$. Ultimately, Retailer 1's equilibrium profit (gross of compliance costs) is

$$
\Pi_{1}=\frac{1}{2}\left(1-\frac{4}{3} \alpha\right)
$$

which is lower than $(1 / 2-\alpha) t$, the profit (gross of the same compliance costs) enjoyed by both retailers upon selecting their competitor's customers.

When $\Delta I$ is so high that they both opt for internal compliance in the reference scenario, the same reasoning applies, only with marginal changes. The density remains equal to 1 for $x>1 / 2$ when Retailer 1 deviates, $(11)$ is still the relevant profit maximization program and it implements the same prices and market profits in equilibrium. In addition, Retailer 1's profit is lower than under internal compliance. In the end, we have:

Proposition 4. Under the assumption that the average investment cost is the same inside and outside the market, the retailers never subsidize energy users outside their market.

\subsection{Trading of obligations}

We have so far ignored the possibility that obligations can be traded among retailers. This flexibility provision is however granted in a few countries, essentially France and the United Kingdom, where obligated retailers can purchase so-called white certificates produced by other parties. We now examine how this affects compliance strategies. Again, we stick to the symmetric-cost assumption.

The Coase Theorem provides a useful framework to go through this analysis. Introducing a market for white certificates gives retailers the opportunity to make binding contracts. Hence, the white certificate market outcome is as if each party committed to a targeting rule. 
Assuming that the market for white certificates is efficient, we know that the parties will agree on a set of transactions that maximizes joint profits. The whole process can then be modelled as a two-stage game where retailers cooperatively select which customers to subsidize in the first stage and non-cooperatively set energy prices in the second stage. With symmetric retailers, the rule maximizing joint profits is the same as the one they would select under 'internal compliance only.'

We can now directly derive the following results:

Proposition 5. When retailers are allowed to trade obligations, they behave as if external compliance were not allowed (see Proposition 1):

- If $\Delta I<\Phi(\alpha, e)$, they target customers with the highest elasticity of demand.

- If $\Delta I \geq \Phi(\alpha, e)$, they target low-cost customers located around $1 / 2$.

As a result, trading (weakly) improves cost-effectiveness relative to a scheme allowing external compliance but prohibiting trade. It also increases the energy price and thus reduces consumer surplus.

Importantly, our result that trading reduces total investment cost differs from the usual argument that, when investment costs vary across retailers, trading helps them identify least-cost options. Our argument relies on the notion that the market for white certificates allows retailers to make binding commitments, thereby preventing free riding. Re-introducing asymmetry in cost across the two customer bases would simply reinforce the result.

\section{Robustness and extensions}

Perhaps the most crucial assumption throughout our analysis has been the symmetry imposed on average investment costs across retailers, both within and outside the market. This assumption was meant to pinpoint how the degree of competition affects the added value of the different flexibility provisions. As stated in Proposition 3, cost heterogeneity provides an argument for enhancing flexibility.

In this section, we discuss the robustness of our results to alternative assumptions. 
Oligopoly. In practice, the number of competing retailers ranges from a few - e.g., twelve in the UK electricity market - to several thousand - e.g., France. We could increase the number of firms in our model by using Salop (1979)'s framework of circular differentiation. Let us consider $n$ energy retailers symmetrically distributed over a circle and a continuum of consumers evenly distributed over it. Each retailer thus directly competes with its two closest neighbors. Our results regarding 'internal compliance only' carry over to this alternative specification. Retailers now consider the middle of the circular portion between them, and their choice between subsidizing low-cost vs. high-elasticity customers still depends on the investment cost differential. When external compliance is permitted, the analysis becomes more tedious. In addition to facing two binary alternatives for external compliance - inside or outside the market -, retailers can now use an intermediate option consisting in subsidizing customers located far away on the circle yet still within the market. This specification would not qualitatively alter our results, for retailers' decisions are driven by the same factors as those driving the choice between targeting inside and outside the market.

Energy prices influencing utility. In our setting, energy users never stop consuming energy services: they enjoy utility $u_{i}(x)$ regardless of whether they invest or not. As a result, price variations only have distributional effects and social welfare maximization is aligned with investment cost minimization. This simplification leads us to overlook the trade-off between internalizing the negative externalities associated with energy use - which is a prime motivation for energy efficiency obligations and is best achieved by raising energy prices - and increasing consumer surplus - which requires lowering prices.

Without engaging in fully-fledged welfare analysis, we can nevertheless examine how incorporating energy prices into consumer utility would modify retailers' behavior and overall cost minimization. Based on Laffont et al. (1998), assume that each customer consumes several units of energy. Under that specification, firms still target those customers located around the middle of the segment in order to raise prices. Their ability to raise prices is however reduced, since higher prices reduce sales from non-subsidized customers. Under internal compliance, retailers would therefore be more likely to subsidize low-cost customers than high-elasticity 
ones. Note that this improves cost-effectiveness. In case they select low-cost customers, the increase in energy prices is also milder (compared to our baseline model). Recall that subsidizing outside a retailer's customer base does not affect energy prices. When external compliance is allowed, energy retailers would therefore more likely target their competitors' customers, which will make external compliance even less cost-effective.

Spatial economies of scale. In practice, investment costs may be reduced by subsidizing a pool of neighboring energy users. It is for instance cheaper to conduct several energy audits on a given street than to audit the same number of homes all located in different neighborhoods. This leads the targeting rule adopted by retailers to affect individual investment costs.

Our framework can accommodate such cost-saving spatial externalities if we allow retailers to flexibly select any group of customers. Under this specification, the cost-effective solution is to target low-cost customers together with their neighbors. Two cases need to be considered. If energy retailers enjoy local monopoly, the probability that their customers' neighbors belong to theirs is high. Allowing external compliance therefore mitigates compliance cost reduction. In contrast, if energy retailers compete uniformly across the territory, then the probability that the neighbors of their low-cost customers belong to their competitors' customers is high. Allowing external compliance can thus reduce compliance costs and therefore be cost-effective.

Residual energy use after investment. Instead of assuming that energy use is zero after investment, we now suppose that investment reduces energy use by a fixed percentage. Under internal compliance, the increase in energy prices will be less than that discussed in Section 4. However, the choice between targeting low-cost vs. high-elasticity customers will not qualitatively change. Under external compliance, the incentives energy retailers have to target their competitors' customers are lower and depend on the percentage reduction in energy use. If it is low enough, energy retailers prefer to subsidize their own customers.

Endogenous loyalty. Until now we have assumed that loyalty toward an energy retailer is exogenous. In practice, however, subsidies can affect loyalty. This could be accommodated in 
our model by shifting a consumer's location by a distance $d$ closer to the retailer offering a subsidy. We would further assume that consumers do not completely stop purchasing energy after investment so that retailers may find it profitable to recruit them into their customer base. This new opportunity to expand sales increases a retailer's incentive to subsidize a competitor's customer, provided the distance covered is sufficient. In contrast, in our baseline specification, energy retailers are not guaranteed to effectively recruit those of their competitor's customers they subsidize, for they randomly target them without knowing their loyalty. The alternative specification discussed here therefore reinforces the result that permitting external compliance can increase investment costs.

Repeated purchase. So far, we have assumed that customers buy energy only once. In the more realistic case where consumers buy energy frequently (say every month), myopic consumers will base their investment decisions on the energy price prevailing at the beginning of the period while retailers will adjust their price at the end of the period. If we add a period to the model, customers who had not invested in the first period will now make their investment decision based on this new, higher price, which in turn will reduce the subsidy cost borne by the retailers. Such a dynamic framework increases the incentives retailers have to adopt selection rules in the first period that increase the energy price - that is, target those customers with the highest elasticity rather than minimize investment costs. If energy savings can be banked so as to be traded in subsequent periods, as is generally granted in practice, retailers face even greater incentives to raise prices in the first periods and make investments later in order to reduce total investment cost.

\section{Conclusion and policy implications}

The main intended benefit of energy efficiency obligations is to delegate the achievement of energy efficiency policy objectives to market agents that are supposedly better informed about energy end-users than is the regulator. Specifically, energy retailers are expected to more finely

identify cost-effective investment opportunities, based on their knowledge of technological and 
behavioral patterns.

We show that imperfect competition, which is the prevailing form of competition in liberalized energy markets, dissipates part of the cost savings expected from delegation. This occurs through two mechanisms. First, energy retailers may not use the relevant piece of information: instead of screening consumers' investment costs, they screen their elasticity. While profits increase, thanks to higher energy prices, total compliance costs are not minimized. The second mechanism arises when external compliance is allowed. Then, retailers are unable to identify those least-cost options that lie within their competitor's customer base.

The two mechanisms jointly operate under external compliance, making it a particularly inefficient flexibility provision. In contrast, under 'internal compliance only,' retailers can select low-cost customers, yet only to the extent that cost heterogeneity is high enough among them. Bad news is that, overall, retailers have incentives to rely on external compliance in order to protect their sales. Good news is that external compliance limits retailers' ability to pass through compliance costs onto energy prices and therefore favors consumers.

As explained in Section 2, most of the European obligation schemes allow both internal and external compliance, but only a few countries - France and the United Kingdom - have enhanced flexibility so much as to allow the trading of obligations between obligated firms. We show that this provision induces a more cost-effective selection rule by mitigating the incentives to rely on external compliance. Specifically, under our assumptions, trading generates an equilibrium mimicking that of internal compliance. The higher cost-effectiveness however comes at the expense of consumers, who pay a higher energy price.

In the end, in liberalized markets subject to imperfect competition, the choice of allowing external compliance, with or without trading, should depend on the relative weights a regulator places on cost-effectiveness and consumer surplus.

\section{Acknowledgements}

We thank three anonymous reviewers, Pierre Fleckinger and Laurent Lamy for useful comments on earlier drafts. 


\section{References}

Allcott, H., Greenstone, M., 2012. Is There an Energy Efficiency Gap? Journal of Economic Perspectives 26, 3-28. https://doi.org/10.1257/jep.26.1.3

Chu, L.Y., Sappington, D.E.M., 2013. Motivating energy suppliers to promote energy conservation. J Regul Econ 43, 229-247. https://doi.org/10.1007/s11149-013-9215-x

Chu, L.Y., Sappington, D.E.M., 2012. Designing optimal gain sharing plans to promote energy conservation. J Regul Econ 42, 115-134. https://doi.org/10.1007/s11149-012-9194-3

Fawcett, T., Rosenow, J., Bertoldi, P., 2019. Energy efficiency obligation schemes: their future in the EU. Energy Efficiency 12, 57-71. https://doi.org/10.1007/s12053-018-9657-1

Fowlie, M., Greenstone, M., Wolfram, C., 2018. Do Energy Efficiency Investments Deliver? Evidence from the Weatherization Assistance Program. Q J Econ 133, 1597-1644. https://doi.org/10.1093/qje/qjy005

Gillingham, K., Palmer, K., 2014. Bridging the Energy Efficiency Gap: Policy Insights from Economic Theory and Empirical Evidence. Rev Environ Econ Policy. https://doi.org/10.1093/reep/ret021

Giraudet, L.-G., Finon, D., 2015. European experiences with white certificate obligations: A critical review of existing evaluations. Economics of Energy and Environmental Policy 4. https://doi.org/10.5547/2160-5890.4.1.lgir

Giraudet, L.-G., Quirion, P., 2008. Efficiency and distributional impacts of tradable white certificates compared to taxes, subsidies and regulations. Revue d'economie politique 118, 885-914.

Hotelling, H., 1929. Stability in Competition. The Economic Journal 39, 41-57. https://doi.org/10.2307/222

IEA [International Energy Agency], 2017. Market-based Instruments for Energy Efficiency Policy Choice and Design

IEA [International Energy Agency], 2018. Market Report Series: Energy Efficiency 2018.

Joskow, P.L., Marron, D.B., 1992. What Does a Negawatt Really Cost? Evidence from Utility Conservation Programs. The Energy Journal 13, 41-74.

Klemperer, P., 1995. Competition when Consumers have Switching Costs: An Overview with Applications to Industrial Organization, Macroeconomics, and International Trade. Rev 
Econ Stud 62, 515-539. https://doi.org/10.2307/2298075

Laffont, J.-J., Rey, P., Tirole, J., 1998. Network Competition: I. Overview and Nondiscriminatory Pricing. The RAND Journal of Economics 29, 1-37. https://doi.org/10.2307/2555814

Lewis, T.R., Sappington, D.E.M., 1992. Incentives for Conservation and Quality-Improvement by Public Utilities. The American Economic Review 82, 1321-1340.

Metcalf, G.E., Hassett, K.A., 1999. Measuring the Energy Savings from Home Improvement Investments: Evidence from Monthly Billing Data. Review of Economics and Statistics 81, 516-528. https://doi.org/10.1162/003465399558274

Salop, S.C., 1979. Monopolistic Competition with Outside Goods. The Bell Journal of Economics 10, 141-156. https://doi.org/10.2307/3003323

Stoft, S., Gilbert, R.J., 1994. A Review and Analysis of Electric Utility Conservation Incentives. Yale J. on Reg. 11, 1.

Wirl, F., 2015. White certificates - Energy efficiency programs under private information of consumers. Energy Economics 49, 507-515. https://doi.org/10.1016/j.eneco.2015.03.026

Wirl, F., 1995. Impact of regulation on demand side conservation programs. J Regul Econ 7, 43-62. https://doi.org/10.1007/BF01062779

\section{Appendix}

\subsection{Proof of Lemma 1}

Let us determine the equilibrium prices when both retailers subsidize their high-elasticity customers. The indifferent customer is defined by $\tilde{x}\left(p_{1}, p_{2}\right)=\frac{1}{2}+\frac{p_{2}-p_{1}}{2 t}$.

First, consider the case $\tilde{x} \in[0,1 / 2-2 \sqrt{\alpha e}]$. The two retailers solve

$$
\begin{aligned}
& \max \Pi_{1}\left(p_{1}, p_{2}\right)=\tilde{x} \times p_{1} \\
& \max \Pi_{2}\left(p_{1}, p_{2}\right)=[1-2 \alpha-\tilde{x}] \times p_{2},
\end{aligned}
$$


leading to

$$
\begin{aligned}
& \frac{\partial \Pi_{1}}{\partial p_{1}}=\frac{1}{2}+\frac{p_{2}-2 p_{1}}{2 t}=0 \\
& \frac{\partial \Pi_{2}}{\partial p_{2}}=\frac{1}{2}-2 \alpha+\frac{p_{1}-2 p_{2}}{2 t}=0 .
\end{aligned}
$$

The problem admits a unique solution such that $p_{1}=t-(4 / 3) \alpha t, p_{2}=t-(8 / 3) \alpha t$ and $\tilde{x}=1 / 2-(2 / 3) \alpha$. However $1 / 2-(2 / 3) \alpha$ does not belong to the interval $[0,1 / 2-2 \sqrt{\alpha e}$. Indeed, $1 / 2-(2 / 3) \alpha<1 / 2-2 \sqrt{\alpha e}$ implies that $e<\frac{\alpha}{9}$, which is impossible.

Second, consider the case $\tilde{x} \in[1 / 2-2 \sqrt{\alpha e}, 1 / 2]$. The two retailers solve

$$
\begin{aligned}
& \max \Pi_{1}\left(p_{1}, p_{2}\right)=[\tilde{x}-F(\tilde{x})] \times p_{1} \\
& \max \Pi_{2}\left(p_{1}, p_{2}\right)=\left[1-2 \alpha-(\tilde{x}-F(\tilde{x})] \times p_{2},\right.
\end{aligned}
$$

leading to

$$
\begin{aligned}
& \frac{\partial \Pi_{1}}{\partial p_{1}}=\tilde{x}-F(\tilde{x})-\frac{1}{2 t}[1-f(\tilde{x})] p_{1}=0 \\
& \frac{\partial \Pi_{2}}{\partial p_{2}}=1-2 \alpha-(\tilde{x}-F(\tilde{x}))+\frac{1}{2 t}[1-f(\tilde{x})] p_{2}=0 .
\end{aligned}
$$

The problem admits a unique solution such that $p_{1}=p_{2}$ and $\tilde{x}=1 / 2$. We thus get

$$
\frac{\partial \Pi_{1}\left(p_{1}, p_{1}\right)}{\partial p_{1}}=1 / 2-F(1 / 2)-\frac{1}{2 t}[1-f(1 / 2)] p_{1}=0 .
$$

Since $F(1 / 2)=\alpha$ and $f(1 / 2)=\sqrt{\alpha / e}$, we deduce that $p_{1}=p_{2}=\frac{1-2 \alpha}{1-\sqrt{\alpha / e}} t .1 / 2$ belongs to $[1 / 2-2 \sqrt{\alpha e}, 1 / 2]$

Now consider the case where $\tilde{x} \in[1 / 2,1 / 2+2 \sqrt{\alpha e}]$. This case is the exact symmetric of the previous case and it leads to the same equilibrium characterized by $p_{1}=p_{2}=\frac{1-2 \alpha}{1-\sqrt{\alpha / e}} t$ and $\tilde{x}=1 / 2$. 
Finally, consider the case $\tilde{x} \in[1 / 2+2 \sqrt{\alpha e}, 1]$. This case is the exact symmetric of the first one and no equilibrium is associated with it.

We conclude that there is a single equilibrium, which is given by $p_{1 l}^{*}=p_{2 l}^{*}=p_{l}^{*}=\frac{1-2 \alpha}{1-\sqrt{\alpha / e}} t$. Since $e<\frac{1}{4 \alpha}$, we get that $1-2 \alpha<1-\sqrt{\alpha / e}$. It follows that $p_{l}^{*}>t$.

\subsection{Proof of Lemma 2}

Each retailer selects those with the highest signals among low-cost customers. Building on the case in which a retailer targets high-elasticity customers, but considering only half of the density, we directly obtain the cumulative distribution of the targeted customers: $G(x)=$ $\frac{1}{2} F(x)$. It follows that

$$
G(x):=\frac{1}{8 e}(x-y)^{2} .
$$

In this expression, $y$ is implicitly defined by the compliance condition $G(1 / 2)=\alpha$. Solving for $y$ leads to $y=1 / 2-2 \sqrt{2 \alpha e}$. Plugging this into the previous expression, we obtain:

$$
G(x)=\frac{1}{8 e}\left(x-\frac{1}{2}+2 \sqrt{2 \alpha e}\right)^{2}
$$

while the density is

$$
g(x)=\frac{1}{4 e}\left(x-\frac{1}{2}+2 \sqrt{2 \alpha e}\right) .
$$

We now directly adapt the proofs of Lemma 1 so as to derive equilibrium prices. We consider four cases, $\tilde{x} \in[0,1 / 2-2 \sqrt{2 \alpha e}], \tilde{x} \in[1 / 2-2 \sqrt{2 \alpha e}, 1 / 2], \tilde{x} \in[1 / 2,1 / 2+2 \sqrt{2 \alpha e}]$ and $\tilde{x} \in[1 / 2+2 \sqrt{2 \alpha e}, 1]$.

First, consider the case $\tilde{x} \in[0,1 / 2-2 \sqrt{2 \alpha e}]$. The two retailers solve

$$
\begin{aligned}
& \max \Pi_{1}\left(p_{1}, p_{2}\right)=\tilde{x} \times p_{1} \\
& \max \Pi_{2}\left(p_{1}, p_{2}\right)=[1-2 \alpha-\tilde{x}] \times p_{2} .
\end{aligned}
$$

As in the proofs of Lemma 1 the problem admits a unique solution so that $p_{1}=t-(4 / 3) \alpha t$, 
$p_{2}=t-(8 / 3) \alpha t$ and $\tilde{x}=1 / 2-(2 / 3) \alpha$. However $1 / 2-(2 / 3) \alpha$ does not belong to the interval $[0,1 / 2-2 \sqrt{2 \alpha e}]$. Indeed, $1 / 2-(2 / 3) \alpha<1 / 2-2 \sqrt{2 \alpha e}$ implies that $e<\alpha / 18$, which is impossible.

Second, consider the case $\tilde{x} \in[1 / 2-2 \sqrt{\alpha e}, 1 / 2]$. The two retailers solve

$$
\begin{aligned}
\max \Pi_{1}\left(p_{1}, p_{2}\right) & =[\tilde{x}-G(\tilde{x})] \times p_{1} \\
\max \Pi_{2}\left(p_{1}, p_{2}\right) & =\left[1-2 \alpha-(\tilde{x}-G(\tilde{x})] \times p_{2},\right.
\end{aligned}
$$

leading to

$$
\begin{aligned}
& \frac{\partial \Pi_{1}}{\partial p_{1}}=\tilde{x}-G(\tilde{x})-\frac{1}{2 t}[1-g(\tilde{x})] p_{1}=0 \\
& \frac{\partial \Pi_{2}}{\partial p_{2}}=1-2 \alpha-(\tilde{x}-G(\tilde{x}))+\frac{1}{2 t}[1-g(\tilde{x})] p_{2}=0 .
\end{aligned}
$$

The problem admits a unique solution so that $p_{1}=p_{2}$ and $\tilde{x}=1 / 2$. We get

$$
\frac{\partial \Pi_{1}\left(p_{1}, p_{1}\right)}{\partial p_{1}}=1 / 2-G(1 / 2)-\frac{1}{2 t}[1-g(1 / 2)] p_{1}=0
$$

Since $G(1 / 2)=\alpha$ and $g(1 / 2)=\sqrt{\alpha /(2 e)}$, we deduce that $p_{1}=p_{2}=\frac{1-2 \alpha}{1-\sqrt{\alpha /(2 e)}} t .1 / 2$ belongs to $[1 / 2-2 \sqrt{2 \alpha e}, 1 / 2]$.

The other two cases are the exact symmetric of the cases we have just dealt with. We

conclude that there is a single equilibrium, which is given by $p_{1 c}^{*}=p_{2 c}^{*}=p_{c}^{*}=\frac{1-2 \alpha}{1-\sqrt{\alpha /(2 e)}} t$. Since $e<1 /(8 \alpha)$, we get that $1-2 \alpha<1-\sqrt{\alpha /(2 e)}$. We deduce that $p_{c}^{*}>t$.

\subsection{Proof of Proposition 1}

First of all, let us determine the profits in the two cases - whether retailers target high-elasticity or low-cost customers.

When retailers target high-elasticity customers, the profit of Firm 1 is 


$$
\pi_{l}^{*}=(1 / 2-\alpha) p_{l}^{*}-\alpha\left(\frac{\bar{I}+\underline{I}}{2}\right)
$$

We deduce that

$$
\pi_{l}^{*}=\frac{(1-2 \alpha)^{2} t}{\alpha(1-\sqrt{\alpha / e})}-\alpha\left(\frac{\bar{I}+\underline{I}}{2}\right) .
$$

When retailers target low-cost customers, the profit of Firm 1 is

$$
\pi_{c}^{*}=(1 / 2-\alpha) p_{c}^{*}-\alpha \underline{I}
$$

We deduce that

$$
\pi_{c}^{*}=\frac{(1-2 \alpha)^{2} t}{\alpha(1-\sqrt{\alpha /(2 e)})}-\alpha \underline{I}
$$

Therefore $\pi_{l}^{*}>\pi_{c}^{*}$ implies:

$$
\bar{I}-\underline{I}<\frac{(1-2 \alpha)^{2} t}{\alpha}\left(\frac{1}{1-\sqrt{\alpha / e}}-\frac{1}{1-\sqrt{\alpha /(2 e)}}\right)
$$

To prove that the two cases studied above are the only Nash equilibria, we analyze the asymmetrical case where Firm 1 subsidizes the least-loyal consumers while Firm 2 targets low-cost ones. We consider four cases: $\tilde{x} \in[0,1 / 2-2 \sqrt{\alpha e}], \tilde{x} \in[1 / 2], 1 / 2], \tilde{x} \in[1 / 2,1 / 2+2 \sqrt{2 \alpha e}]$ and $\tilde{x} \in[1 / 2+2 \sqrt{2 \alpha e}, 1]$.

First, building on the proofs of Lemma 1 and Lemma 2 , no equilibrium $\tilde{x}$ exists in $[0,1 / 2-$ $2 \sqrt{\alpha e}]$ and $[1 / 2+2 \sqrt{2 \alpha e}, 1]$.

Second, consider the case $\tilde{x} \in[1 / 2-2 \sqrt{\alpha e}, 1 / 2]$. The two retailers solve

$$
\begin{aligned}
& \max \Pi_{1}\left(p_{1}, p_{2}\right)=[\tilde{x}-F(\tilde{x})] \times p_{1} \\
& \max \Pi_{2}\left(p_{1}, p_{2}\right)=\left[1-2 \alpha-(\tilde{x}-F(\tilde{x})] \times p_{2},\right.
\end{aligned}
$$

leading to the equilibrium characterized by $p_{1}=p_{2}=\frac{1-2 \alpha}{1-\sqrt{\alpha / e}} t$ and $\tilde{x}=1 / 2$. 
Consider now the case $\tilde{x} \in[1 / 2,1 / 2+2 \sqrt{2 \alpha e}]$. The two retailers solve

$$
\begin{aligned}
\max \Pi_{1}\left(p_{1}, p_{2}\right) & =[\tilde{x}-G(\tilde{x})] \times p_{1} \\
\max \Pi_{2}\left(p_{1}, p_{2}\right) & =\left[1-2 \alpha-(\tilde{x}-G(\tilde{x})] \times p_{2},\right.
\end{aligned}
$$

leading to the equilibrium characterized by $p_{1}=p_{2}=\frac{1-2 \alpha}{1-\sqrt{\alpha /(2 e)}} t$ and $\tilde{x}=1 / 2$.

Two symmetrical equilibria are therefore possible and lead to $\tilde{x}=1 / 2$. However, the

equilibrium with $p_{1}=p_{2}=\frac{1-2 \alpha}{1-\sqrt{\alpha / e}} t$ is unstable: If Firm 1 lowers its price to increase its market share, then $\tilde{x}$ lies between $1 / 2$ and $1 / 2+2 \sqrt{2 \alpha e}$, which leads to the equilibrium with $p_{1}=p_{2}=\frac{1-2 \alpha}{1-\sqrt{\alpha /(2 e)}} t$. We deduce that the only stable equilibrium is $p_{1}=p_{2}=\frac{1-2 \alpha}{1-\sqrt{\alpha /(2 e)}} t$.

We now go back to the first stage and wonder whether the two situations - the two retailers targeting either high-elasticity or low-cost customers - are Nash equilibria. Consider the first one and suppose that condition 17 is satisfied. If one retailer deviates and targets low-cost customers, it will reap the same profit as if both retailers targeted low-cost customers. This profit will be lower than if both targeted the high-elasticity customers.

Now consider the second case - both retailers subsidize low-cost customers - and assume that condition $(17)$ is violated. If one energy retailer deviates, it will sell the same quantity of energy at the same price but will bear a higher investment cost. We conclude that, in either case, it is in no retailer's interest to deviate.

\subsection{Proof of Lemma 3}

We consider the case where Firm 1 targets its high-elasticity customers while Firm 2 randomly selects customers among those of Firm 1 that Firm 1 does not subsidize.

First, we identify the customer distribution after investment. Obviously, Firm 1's targeting rule leads it to remove customers following the cumulative distribution $F(x)$ given by Eq. (5). Firm 2 then randomly selects $\alpha$ customers of Firm 1 among the $1 / 2-\alpha$ that remain not subsidized by Firm 1. Uniformly selecting these customers is equivalent to selecting each of them with the same probability $\frac{\alpha}{1 / 2-\alpha}$. To simplify notations, let $\gamma$ denote this probability. Hence, we have: $h(x)=f(x)+\gamma(1-f(x))$ where $h(x)$ denote the density of the selected 
customers. The cumulative distribution $H(X)$ is such that $H(1 / 2)=2 \alpha$, implying that $H(x)=(1-\gamma) F(x)+\gamma x$.

Let us now examine the market stage. In the case where the indifferent consumer falls within $[1 / 2-2 \sqrt{\alpha e}, 1 / 2]$, the demand faced by Retailer 1 is $\tilde{x}-H(\tilde{x})=(1-\gamma)(\tilde{x}-F(\tilde{x}))$ and that faced by Retailer 2 is $1-2 \alpha-(1-\gamma)(\tilde{x}-F(\tilde{x})$. The two retailers therefore solve

$$
\begin{aligned}
\max \Pi_{1}\left(p_{1}, p_{2}\right) & =(1-\gamma)[\tilde{x}-F(\tilde{x})] \times p_{1} \\
\max \Pi_{2}\left(p_{1}, p_{2}\right) & =[1-2 \alpha-(1-\gamma)(\tilde{x}-F(\tilde{x}))] \times p_{2},
\end{aligned}
$$

which, ignoring the constraints falling on $\tilde{x}$, leads to

$$
\begin{aligned}
& \frac{\partial \Pi_{1}}{\partial p_{1}}=(1-\gamma)\left[\tilde{x}-F(\tilde{x})-\frac{1}{2 t}[1-f(\tilde{x})] p_{1}\right]=0 \\
& \frac{\partial \Pi_{2}}{\partial p_{2}}=1-2 \alpha-(1-\gamma)\left[\tilde{x}-F(\tilde{x})-\frac{1}{2 t}(1-f(\tilde{x}))\right] p_{2}=0
\end{aligned}
$$

The important point here is that Firm 1's best-response function 1 is the same as that observed under the scenario where both firms target their high-elasticity customers. This means that, if Firm 2 chooses the price set in equilibrium without deviation, $p_{2}=\frac{1-2 \alpha}{1-\sqrt{\alpha / e}}$, the best response of Firm 1 is $p_{1}=p_{2}$. The only difference with the no-deviation scenario is that Firm 2 now sells a quantity $1 / 2$ instead of $1 / 2-\alpha$, and thus makes more profit.

Plugging this pair of prices into the second first-order condition makes it clear that this is not the equilibrium. However, we know that the response of Firm 2 to this price $p_{1}$ cannot increase Firm 2's profit (otherwise, the firm will not do it). As a result, Firm 2 always makes more profit when subsidizing its competitor's customers, implying that Firm 2 deviates from the equilibrium in which both retailers target high-elasticity customers.

\subsection{Proof of Lemma 4}

Let us focus on the case in which the investment cost differential is such that $\Delta I \geq \Phi(\alpha, e)$ and consider that both firms target their customers with low investment costs. Suppose now that Firm 1 decides to subsidize one customer of Firm 2 instead of subsidizing one of its own. 
Firm 1 subsidizes either a low-cost or a high-cost customer and the incentive cost is equal to $E(I)-t$. However, if Firm 1 subsidizes a customer with low investment costs, the incentive cost is $\underline{I}$. By doing so, Firm 1 increases its sales by one unit but also increases the amount of the subsidy. By subsidizing one of its competitor's customers, Firm 1 will lower the equilibrium price. We immediately conclude that it is not in the interest of Firm 1 to implement this strategy if $\Delta I>2 p_{c}$.

We then compare the two thresholds $\Phi(\alpha, e)$ and $2 p_{c}$ and show that $\Phi(\alpha, e)>2 p_{c}$ is equivalent to $\frac{1-2 \alpha}{1-\sqrt{\alpha / e}}>\frac{1}{1-\sqrt{\alpha /(2 e)}}$.

Let us denote $A=\frac{1-2 \alpha}{1-\sqrt{\alpha / e}}$ and $B=\frac{1}{1-\sqrt{\alpha /(2 e)}}$. If $\alpha=0,03$ and $e=1$, then $A=1,13$ and $B=1,18$. If $\alpha=0,03$ and $e=0,05$, then $A=4,17$ and $B=3,41$. This illustrates that the threshold $A$ may be larger or smaller than the threshold $B$. 